\title{
Have any effect of COVID-19 lockdown on environmental sustainability? A study from most polluted metropolitan area of India
}

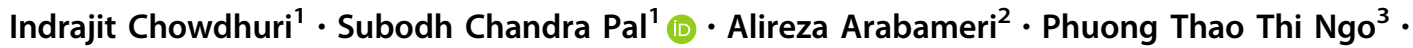 \\ Paramita Roy ${ }^{1} \cdot$ Asish Saha $^{1} \cdot$ Manoranjan Ghosh ${ }^{4} \cdot$ Rabin Chakrabortty $^{1}$
}

Accepted: 2 April 2021 / Published online: 8 April 2021

(C) The Author(s), under exclusive licence to Springer-Verlag GmbH Germany, part of Springer Nature 2021

\begin{abstract}
The long-term lockdown due to COVID-19 has beneficial impact on the natural environment. India has enforced a lockdown on 24th March 2020 and was subsequently extended in various phases. The lockdown due to the sudden spurt of the COVID-19 pandemic has shown a significant decline in concentration of air pollutants across India. The present article dealt with scenarios of air quality concentration of air pollutants, and effect on climatic variability during the COVID-19 lockdown period in Kolkata Metropolitan Area, India. The result showed that the air pollutants are significantly reduced and the air quality index (AQI) was improved during the lockdown months. Aerosol concentrations decreased by $-54.94 \%$ from the period of pre-lockdown. The major air pollutants like particulate matters $\left(\mathrm{PM}_{2.5}, \mathrm{PM}_{10}\right)$, sulphur dioxide $\left(\mathrm{SO}_{2}\right)$, carbon monoxide $(\mathrm{CO})$ and Ozone $\left(\mathrm{O}_{3}\right)$ were observed the maximum reduction $(-40$ to $-60 \%)$ in the COVID-19 lockdown period. The AQI has been improved by $54.94 \%$ in the lockdown period. On the other hand, Sen's slope rank and the Mann-Kendal trend test showed the daily decreased of air pollutants rate is -0.051 to $-1.586 \mu \mathrm{g} /$ $\mathrm{m} 3$. The increasing trend of daily minimum, average, and maximum temperature from the month of March to May in this year (2020s) are $0.091,0.118$, and $0.106{ }^{\circ} \mathrm{C}$ which is lowest than the $2016 \mathrm{~s}$ to $2019 \mathrm{~s}$ trend. Therefore, this research has an enormous opportunity to explain the effects of the lockdown on air quality and climate variability, and it can also be helpful for policymakers and decision-makers to enact appropriate measures to control air pollution.
\end{abstract}

Keywords COVID-19 · Air quality · Climatic variability · Temperature $\cdot$ Kolkata metropolitan area

\section{Introduction}

Corona virus diseases (COVID-19) have become a global concern. This virus was first detected in Wuhan, China, and still (6 May, 2020) has more than 4 million total cases worldwide. On 30 January, the WHO declared such diseases to be a pandemic. With respect to current information 6th May 2020, 3 lakhs (7.06 per cent of the total active case) people are died and 1,049,260 (31.60 per cent of the total active case) recovered from the global population. Finally, the global lockdown with strict rules has resulted to the fight against this situation (Pal et al. 2021). Apart from the lockdown, a number of studies have tried to find cost-effective drugs to control COVID-19 prophylactically or at the earliest stage of infection. One of the most potentially rapid ways to do this is to screen chemical

Extended author information available on the last page of the article libraries and Target-based scanning in order to accelerate clinical assessment (Eydoux et al. 2021). When the WHO confirmed that it was a pandemic, India first placed restrictions on travel to China, Italy, Iran, and the United States on 11 March. The south-western part of the country, such as Maharashtra, Kerala, and the northern part of Delhi, was affected initially. Then the government decided to lock up mass gathering places, like shopping malls, institutions and industrial workplaces etc. The 22nd March was the first day of lockdown for fourteen hours ( 7 am to $9 \mathrm{pm}$ ). Another 21 days of full lockdown started from March 24th to April 14th and it was extended up to 3rd May. Later, the lockdown was jumped to May 17th and finally extended up to May 31st. After the announcement of lockdown, the Government and administration take a hard decision to implement the lockdown as result of no social gathering, substantially reduced the vehicles and public 
transport and fully closed the industries, shopping mall and non-emergency administrative buildings etc.

COVID-19 also had a direct effect on manufacturing and commercial activities, and the adoption of comprehensive and selective lockdown policies ensures that the post-COVID economic and social objectives are in stark contrast to the pre-COVID-19 timeline (Bashir et al. 2020). Bilal et al. (2021) studied air pollutants on the impact of COVID-19 dynamics and in twelve South American states, and stated that there is a significant coherence between total active cases, recovery, total confirmed deaths and emissions of $\mathrm{PM}_{2.5}, \mathrm{PM}_{10}, \mathrm{NO}_{2}, \mathrm{CO}, \mathrm{SO}_{2}$, and $\mathrm{O}_{3}$. A variety of recent literatures have looked at the impact of temperature in the distribution of COVID-19 in various contexts. Bashir et al. (2021) carried out a systematic review on the relationship between the COVID-19 pandemic and the temperature, and most of the studies were failed to detect a direct relationship between the COVID19 pandemic and the temperature. During this vulnerable period, the air has achieved its quality and has made it healthy. Muhammad et al. (2020) have shown that the world's most polluted urban areas, such as China, Spain, France, Italy and USA, have reduced Nitrogen dioxide $\left(\mathrm{NO}_{2}\right)$ emissions up to 20 to 30 per cent during the COVID19 lockdown period. Delhi, the capital city of India, significantly improved air quality and reduced the rate of selective air pollutants during the lockdown period (Mahato et al. 2020). Concentration of air pollutants have been decreased rapidly in urban areas during this period (Mahato et al. 2020). There is a positive relationship between air pollutants and aerosol concentrations (Kaufman and Fraser 1983; Mandal and Pal 2020) and, due to the decrease in major air pollutants, the aerosol concentrations have also reduced. According to the report of the Central Pollution Control Board (CPCB), 88 cities of India reduced the level of air pollution dramatically after the first four days of lockdown (Sharma et al. 2020). In the time of pandemic situation several researches revealed that the lockdown period is capable to reduce the level of air pollutants and its associated aerosol concentration.

Out of the four megacities of India, Kolkata is the third largest metropolitan area in terms of population, with 14.3 million people, covering $205 \mathrm{~km}^{2}$, including urban and sub-urban areas. The KMA is considered as a one of the densely populated region of the world with 24,306 people $/ \mathrm{km}^{2}$ population density. Increasing population and growing commercial sectors are positively correlated to each other, which increase the level of pollution caused by traffic, industrial activities and the daily needs for accessories. In 2016 the capital city of West Bengal alone holds 740 thousands registered vehicles. Apart from this, jute mill on both sides of the Hooghly river bank, power generation, coal industries were indirectly linked to the water and air pollution (Mondal et al. 2018). According to WHO (World Health Organization) standards, Kolkata needs to reduce average $\mathrm{PM}_{10}$ by $98 \%$ from the current baseline (Gurjar et al. 2010). The KMA administration has implemented strict measures, such as the closing of malls, shops, shopping centres, all factories, public transport and airports, etc.

Consequently, the restriction on emissions of pollutants from commercial sectors brings with a change in both air quality and the environment. Weather and climatic elements have an important role in air quality patterns and emission of pollutants. Meteorological variables such as temperature, relative humidity, wind direction and mixing heights may affect air pollutants and air quality (Kinney 2008). A study of Tayanç et al. (1997) showed that Turkey's annual and seasonal trends in air temperature patterns have changed due to rapid urbanization and its associated air pollutants. This study also shows that the average temperature was reduced in the northern part of Turkey by the low accumulation of air pollutants. On the other hand, increases the minimum temperature was also increased in specific large urban areas. There is a direct impact of air pollutants on the climate and its variability in continuous way (Smith 1970). Chowdhuri et al. (2020) showed that there was a significant decrease in pre-monsoon lightning activities during the COVID-19 lockdown period over the Kolkata megacity. Reduction of $\mathrm{PM}_{10}, \mathrm{NO}_{2}, \mathrm{SO}_{2}, \mathrm{O}_{3}$ and aerosol concentrations in lower atmosphere due to COVID19 lockdown was the main cause of low lightning rates over Kolkata.

So different studies have shown that air quality is improving and air pollutant levels are rapidly declining due to the lockdown in urban areas (Mahato et al. 2020; Mandal and Pal 2020; Pal et al. 2020; Sharma et al. 2020; Yunus et al. 2020). The concentration of pollutants and the change in climatic variability yet not explored clearly through the trend analysis approach. The main objectives of this study are therefore to estimate the changing trend in temperature and the impact on climatic variability due to the declining trend in aerosol concentrations along with the changing major air pollutants during the lockdown in the Kolkata metropolitan area (KMA).

\section{Material and methods}

\subsection{Study area}

Kolkata is the capital city of West Bengal, as the administrative capital of the British Indian Empire, formerly known as Calcutta. It is the seven-largest city and the thirdlargest metropolitan area of India, covering $1886.67 \mathrm{~km}^{2}$ with a population of 14.85 million and a population density 
of 7480 per $\mathrm{km}^{2}$. The city of Kolkata is the eastern gateway of the Indian subcontinent to the Kolkata port, which has been famous for trade and commerce since the British era. The area of Kolkata is $185.39 \mathrm{~km}^{2}$ which is located between the coordinate of $88^{\circ} 18^{\prime} \mathrm{E}$ to $88^{\circ} 23^{\prime} \mathrm{E}$ and $22^{\circ}$ $30^{\prime} \mathrm{N}$ to $22^{\circ} 37^{\prime} \mathrm{N}$. Geographically, Kolkata is located on the eastern bank of the Hoogly River, forming a new alluvial deposit. It is part of the Ganga and Brahmaputra delta of Bengal and is at a very low altitude of $1.5 \mathrm{~m}$ to $9 \mathrm{~m}$ from the mean sea level (MSL). The megacity is attached to many cities in the KMA, e.g. Howrah and Uluberia of Howrah, Barasat and Barrackpore of North 24 Parganas, Baruipur and Budge Budge of South 24 Parganas and Gayespur and Kalyani of Nadia, Serampore and Dankuni of Hooghly district. The city faces tropical, dry climate with five seasons, i.e. summer (Apr to May), monsoon (June to Sep), post-monsoon (Oct to Nov), winter (Dec to Jan) and pre-monsoon (Feb-Mar). The mean annual monthly temperature is $26^{\circ} \mathrm{C}$ and the ranges of temperatures in summer and winter are $27^{\circ} \mathrm{C}$ to $37^{\circ} \mathrm{C}$ and $12{ }^{\circ} \mathrm{C}$ to $23{ }^{\circ} \mathrm{C}$ respectively. It has been well recognised in several reports and literatures that the Kolkata is one of the polluted cities in India. Relatively higher concentrations of $\mathrm{PM}_{2.5}, \mathrm{PM}_{10}, \mathrm{SO}_{2}, \mathrm{NO}_{2}$ and $\mathrm{NH}_{3}$ were observed in this area due to the existence of factories, power plants, transport, construction activities, etc. (Gupta et al. 2008; Haque and Singh 2017). Now, as part of the air quality study, 10 air monitoring stations in Kolkata have considered for this study and their location is shown in Fig. 1.

\subsection{Database}

Various types of data were taken during the COVID-19 lockdown on the air quality and regional climate phenomenon assessment of KMA. Seven air pollutants $\left(\mathrm{PM}_{2.5}\right.$, $\mathrm{PM}_{10}, \mathrm{NO}_{2}$, Ammonia $\left(\mathrm{NH}_{3}\right), \mathrm{SO}_{2}, \mathrm{CO}$ and $\left.\mathrm{O}_{3}\right)$ are hourly data collected from the Indian $\mathrm{CPCB}$ online air quality index portal (National Air Quality Index, 2020; CPCB|Central Pollution Control Board 2020). 10 air monitoring stations in different parts of Kolkata have been taken into account in order to analyse the air quality of KMA. The other dimension of this study is the temperature trend analysis, so the daily and monthly maximum, minimum and average temperature data have been collected from the India Meteorological Department (IMD) in Kolkata. Daily temperature data collected during the months of March, April and May of 2016 to 2020 and monthly data collected between 1980 and 2020 for the same periods.

\subsection{Methodology}

\subsubsection{Aerosol concentration (AC)}

Aerosol accumulation is calculated using a number of methods, but Remote Sensing (RS) data utilizing the Geographic Information System (GIS) methodology is better and time-saving strategies. For this analysis, aerosol concentrations were determined using the results of the Moderate Resolution Imaging Spectroradiometer (MODIS) (Shaw and Gorai 2018). MODIS Terra and Aqua satellite data are provided by the National Aeronautics and Space Administration (NASA) which receives two aerosol optical depth (AOD) measurements every day (at 10:30 and 13:30 local time) (Chang et al. 2014). MODIS Terra Regular level 2 and 3 data of $10 \times 10 \mathrm{~km}$ and $1^{\circ} \times 1^{\circ}$ pixel size of $550 \mathrm{~nm}$ wavelength were used in this analysis (Alam et al. 2011). Following the abstraction of the AOD standard for selected metropolitan areas (Shaw and Gorai 2018), the $\mathrm{PM}_{2.5}$ results were related through regression analysis and Pearson correlation techniques (Chang et al. 2014; Mhawish et al. 2018). The calculations of the mathematical downscaling approach for the extraction of aerosol concentrations are based on the AOD shown below (Chang et al. 2014).

$A C(s, t)=\alpha_{0}(s t)+\alpha_{1}(s, t) A O D(s, t)+\varepsilon(s, t)$

$\alpha_{0}(s t)=\beta_{0}(s)+\beta_{0}(t)+\gamma_{0} Z_{0}$

$\alpha_{1}(s, t)=\beta_{1}(s)+\beta_{1}(t)+\gamma_{1} Z_{1}$

where the $A C(s, t)$ is the concentration of aerosol, the $A C(s$, $t)$ is the intercept and slope at the same position and day, and the $A C(s, t)$ is the residual defect. From the preceding calculation, we have the accumulation amount of aerosol for each day in KMA.

\subsubsection{AQI}

AQI is a general understanding to people that nearby air is good or bad for health, and decision-makers have been helped to develop mitigation measures for air quality management (Kumar and Goyal 2011). The AQI was mainly used to assess the relative change in the concentration of air pollutants in the atmosphere over a two periods or two regions (Chelani et al. 2002). AQI follows the guidelines for air quality that are widely generated, taking into account each major air pollutant and associated health effects at a given location ( $\mathrm{Li}$ et al. 2019). Conventionally, maximum sub-index approaches using five criteria of pollutants used to calculated the AQI (Sharma et al. 2003). In order to assess the air quality for this study we used the India-AQI method following the revised Indian National Air Quality Standards (INAQS) (National Air 


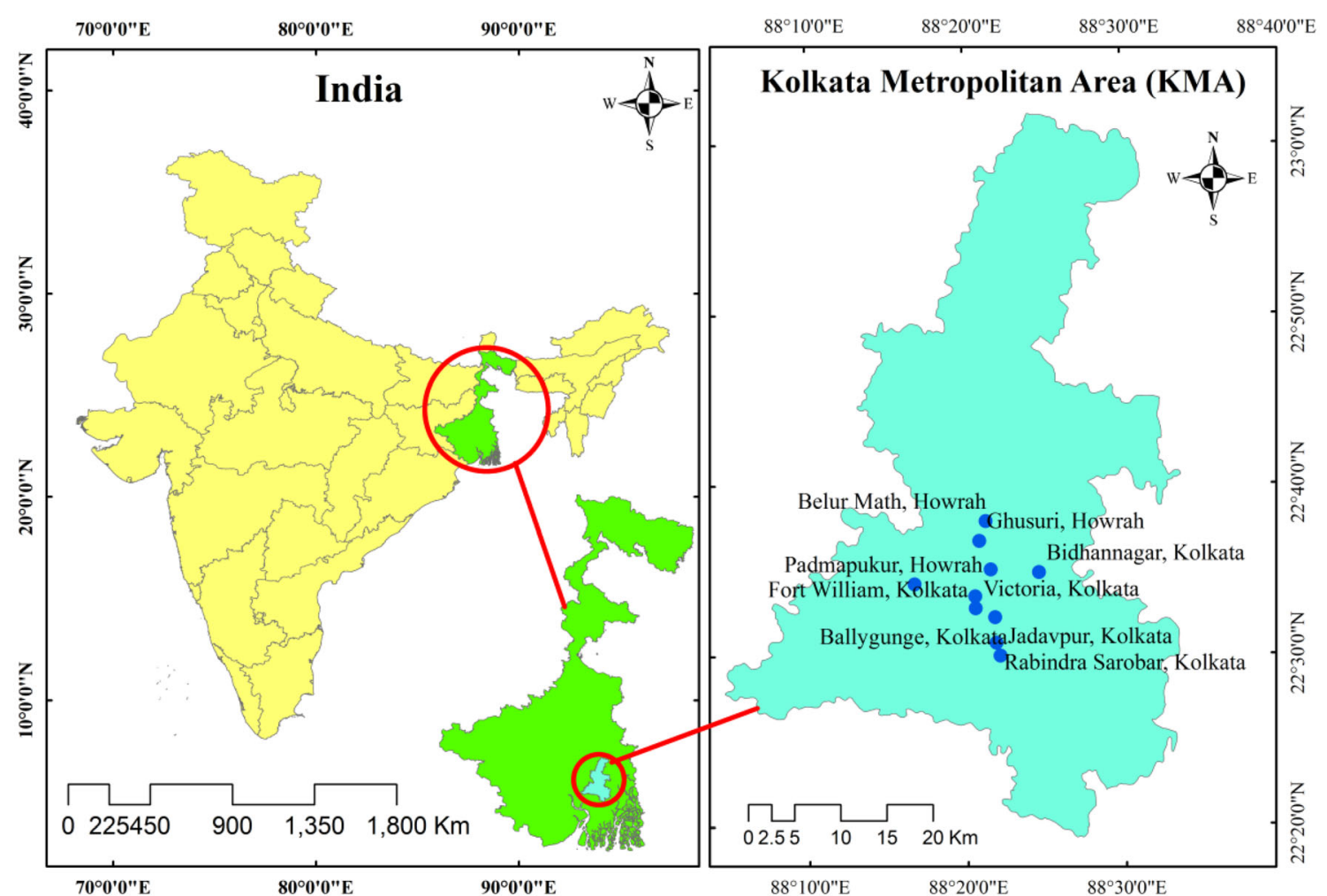

Fig. 1 Location of the Kolkata metropolitan area (KMA)

Quality Index 2020). Seven air pollutants, i.e. $\mathrm{PM}_{2.5}, \mathrm{PM}_{10}$, $\mathrm{NO}_{2}, \mathrm{NH}_{3}, \mathrm{SO}_{2}, \mathrm{CO}$ and $\mathrm{O}_{3}$, were therefore collected with an annual standard with duration of $24 \mathrm{~h}$. The AQI values of all Kolkata metropolitan stations have been calculated by the sub-index value. The sub-index value was calculated using the following equation (Kumar and Goyal 2011; Gupta and Dhir 2019).

$q=100\left(V / V_{s}\right)$ where, $\mathrm{q}=$ Quality Rating, $\mathrm{V}=$ Observed values of the parameter, and Vs = Standard value recommended for the parameter. Thus, one of the pollutant's sub-indexes has the highest value and it is responsible for air quality in a station. Alongside the highest sub-index's pollutant concentration value is the AQI. The value of India-AQI ranges from 0 to 500 and it is categorized into six categories. Table 1 shows the different quality classes of AQI with the health breakpoints (National Air Quality Index 2020).

Table 1 National AQI classes, health impacts and health breakpoints for the seven Pollutants

\begin{tabular}{|c|c|c|c|c|c|c|c|c|}
\hline AQI class (Range) & Health impact & $\begin{array}{l}\mathrm{PM}_{2.5} \\
24 \mathrm{~h} \\
\text { Concentra }\end{array}$ & $\begin{array}{l}\mathrm{PM}_{10} \\
24 \mathrm{~h} \\
\text { tion range }\end{array}$ & $\begin{array}{c}\mathrm{NO}_{2} \\
24 \mathrm{~h} \\
(\mathrm{mg} / \mathrm{m} 3, \mathrm{a}\end{array}$ & $\begin{array}{l}\mathrm{NH}_{3} \\
24 \mathrm{~h} \\
\text { a } \mu \mathrm{g} / \mathrm{m} 3 \text { ) }\end{array}$ & $\begin{array}{l}\mathrm{SO}_{2} \\
24 \mathrm{~h}\end{array}$ & $\begin{array}{l}\mathrm{CO} \\
8 \mathrm{~h}\end{array}$ & $\begin{array}{l}\mathrm{O}_{3} \\
8 \mathrm{~h}\end{array}$ \\
\hline Good $(0-50)$ & Minimal Impact & $0-30$ & $0-50$ & $0-40$ & $0-200$ & $0-40$ & $0-1$ & $0-50$ \\
\hline Satisfactory (51-100) & Minimal Impact & $31-60$ & $51-100$ & $41-80$ & $201-400$ & $41-80$ & $1.1-2$ & $51-100$ \\
\hline $\begin{array}{l}\text { Moderately polluted } \\
\quad(101-200)\end{array}$ & $\begin{array}{l}\text { Breathing discomfort to the people with } \\
\text { lung }\end{array}$ & $61-90$ & $101-250$ & $81-180$ & $401-800$ & $81-380$ & $2.1-10$ & $101-168$ \\
\hline Poor (201-300) & $\begin{array}{l}\text { Breathing discomfort to people on } \\
\text { prolonged exposure }\end{array}$ & $91-120$ & $251-350$ & $181-280$ & $801-1200$ & $381-800$ & $10-17$ & 169-208 \\
\hline Very poor $(301-400)$ & $\begin{array}{l}\text { Respiratory illness to the people on } \\
\text { prolonged exposure }\end{array}$ & $121-250$ & $351-430$ & $281-400$ & $1200-1800$ & $801-1600$ & $17-34$ & $209-748$ \\
\hline Severe $(401-500)$ & $\begin{array}{l}\text { Respiratory illness to the people on } \\
\text { prolonged exposure }\end{array}$ & $>250$ & $>430$ & $>400$ & $>1800$ & $>1600$ & $>34$ & $>748$ \\
\hline
\end{tabular}

Source National Air quality Index portal and Central Pollution Control Board, Govt. of India 2020 


\subsubsection{Mann-Kendall (MK) trend test}

The MK trend test was developed on the basis of the correlation coefficient between the time series and their time order, which defines the growing and declining trend in the time series. (Gocic and Trajkovic 2013). The MannKendall test was first applied in the null-hypothesis test where the data are independent and randomly assigned (Hamed and Rao 1998). The Mann-Kendall statistical S test is calculated as follows (Mann 1945; Kendall 1975).

$S=\sum_{i<j} a_{i j}$

$a_{i j}=\operatorname{sign}\left(X_{j}-X_{i}\right)=\operatorname{sign}\left(R_{j}-R_{i}\right)=\left\{\begin{array}{cc}1 & X_{i}<X_{j} \\ 0 & X_{i}=X_{j} \\ 1 & X_{i}>X_{j}\end{array}\right\}$

Here, $R_{i}$ and $R_{j}$ are rank of observation in $X_{i}$ and $X_{i}$ time series. Mann (1945) and Kendall (1975) have reported that statistics $\mathrm{S}$, with the mean and variance and the variance is computed as

$E(s)=0$

$V_{0}(S)=\frac{n(n-1)(2 n+5)}{18}$

$V_{0}^{*}(S)=\frac{n(n-1)(2 n+5)}{18}-\sum_{j=1}^{m} t_{j}\left(t_{j}-1\right)\left(2_{t j}+5\right) / 18$

where $\mathrm{n}$ is the number of observations, $\mathrm{m}$ is the number of groups of tied ranks, each with $t_{j}$ tied observations. When the number of observation became large the significance of trend can be computed comparing the standardized variable $u$ as followed.

$u=\left\{\begin{array}{cc}(S-1) / \sqrt{V_{0}(S)} & S>0 \\ 0 & S=0 \\ (S+1) / \sqrt{V_{0}(S)} & S<0\end{array}\right\}$

\subsubsection{Sen's slope estimator}

Most of the climate trend studies Sen's slope estimator method used for the Mann-Kendall trend test. When a linear slope is present in time data, the true slope (per unit of time) can be calculated by the Sen's Slope Estimator and developed Sen 1968. The following equation was used to calculate the slope estimates of the $\mathrm{N}$ datasets.

$Q_{i}=\frac{x_{j}-x_{k}}{j-k}$ for $i=1,2, \ldots \ldots \ldots \ldots \ldots, N$

where $x_{j}$ and $x_{k}$ are the value of data at the time $\mathrm{j}$ and $\mathrm{k}$ $(j>k)$, respectively. The median of slope or Sen's slope estimator of odd and even data is computed as

$Q_{m}=Q_{[(N+1) / 2]}$

$Q_{m}=\frac{1}{2}\left[Q_{(N / 2)}+Q_{\{(N+2) / 2\}}\right]$

where $Q_{m}$ is median of data trend. Equation 8 applied if $\mathrm{N}$ is odd data and if $\mathrm{N}$ is even Eq. 9 is used. When the median slope is statistically different than zero then confidence interval of $Q_{m}$ at specific probability (Gilbert 1987; Da Silva et al. 2015) estimated as

$C_{\alpha}=Z_{1-\frac{\alpha}{2}} \sqrt{\operatorname{Var}(S)}$

where $\operatorname{Var}(\mathrm{S})$ is calculated from the Eq. (9) and $Z_{1-\alpha / 2}$ is obtained from the standard normal distribution.

\section{Results}

\subsection{Overall variation and trend of major air pollutants and aerosol}

This long-term strict lockdown led to an improvement in air quality by reducing the concentration of major air pollutants $\left(\mathrm{PM}_{2.5}, \mathrm{PM}_{10}, \mathrm{CO}, \mathrm{NO}_{2}, \mathrm{SO}_{2}, \mathrm{NH}_{3}\right.$, and $\left.\mathrm{O}_{3}\right)$, particularly in the metropolitan and urban industrial hubs. The spatial variations of $\mathrm{PM}_{2.5}, \mathrm{PM}_{10}, \mathrm{CO}, \mathrm{NO}_{2}, \mathrm{SO}_{2}, \mathrm{NH}_{3}$, $\mathrm{O}_{3}$, and AQI in KMA from 17 February to 6 May were developed by interpolation method (Inverse distance weighting) in ArcGIS 10.4 environment which are shown in Figs. 2 and 3. As we all know, the lockdown started in India after 23 March, so the AQI improved a lot from the first day of lockdown compared to the previous week. This can be clearly distinguished from the spatial map of the various pollutants during the lockdown and pre-lockdown scenarios that pollutants are significantly reduced from the $24^{\text {th }}$ of March and follow-up to the 6th of May (Figs. 2 and $3)$. Before the lockdown, the concentration of high air pollutants is only associated within Kolkata and rest of the portion is associated with moderate to high air pollutants, but after the lockdown, the concentration is low in entire the KMA. The concentrations of $\mathrm{PM}_{2.5}$ and $\mathrm{PM}_{10}$ decreased dramatically from 24th March and the net variation from before lockdown to after lockdown was -81.02 and -68.93 per cent. In the case of the $\mathrm{PM}_{2.5}$ concentration, it increased after 14 April because in India, after the second phase of the lockdown, some essential industries and vehicles were relieved (Fig. 5). Other air pollutants such as $\mathrm{NO}_{2}, \mathrm{NH}_{3}$ and $\mathrm{SO}_{2}$ slowly change the concentration level after the initial lockdown. But when the lockdown takes place in the second and third phases, the above-mentioned air pollutants are slowly declining and 


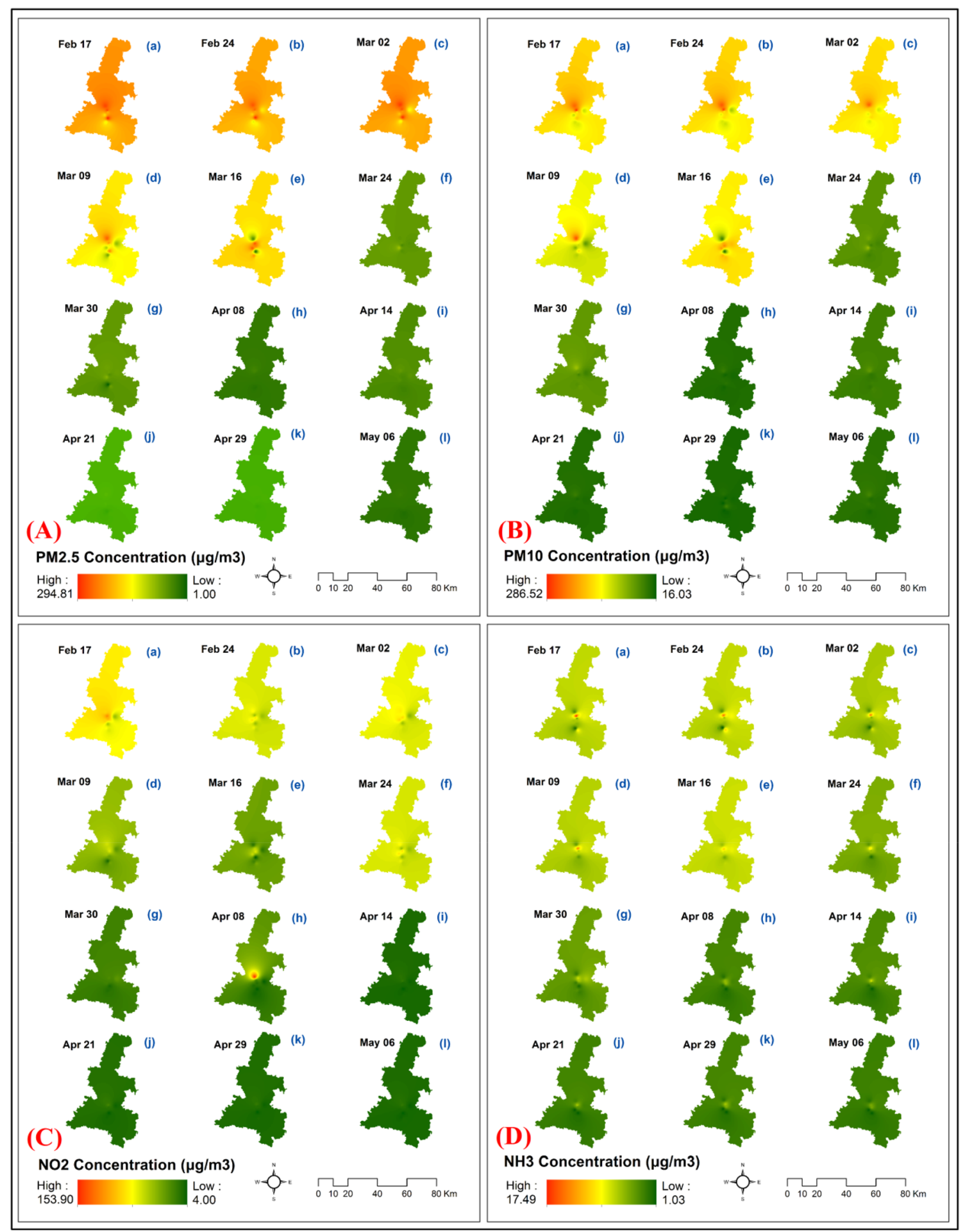

Fig. 2 Spatial status of $\mathbf{A} \mathrm{PM}_{2.5}, \mathbf{B} \mathrm{PM}_{10}, \mathbf{C ~ N O}$, and $\mathbf{D ~ N H}$ in pre-lockdown (a to e) and during lockdown period (f to I) over Kolkata metropolitan area

the concentration is below the permissible level by 6 May. The overall variation of $\mathrm{NO}_{2}, \mathrm{NH}_{3}$ and $\mathrm{SO}_{2}$ is -56.95 , -45.96 and -61.77 per cent. Green house gases, i.e. CO and $\mathrm{O}_{3}$, also have the same spatial trend (Table 2). The concentration of CO suddenly decreased on the 24th of
March and reached below the permissible level. If we see the spatial map of the concentration of $\mathrm{O}_{3}$ : the concentration decreased dramatically on the lockdown day but increased in the next week (Fig. 3.c). The overall variations of $\mathrm{CO}$ and $\mathrm{O}_{3}$ in pre-lockdown and lockdown period are 


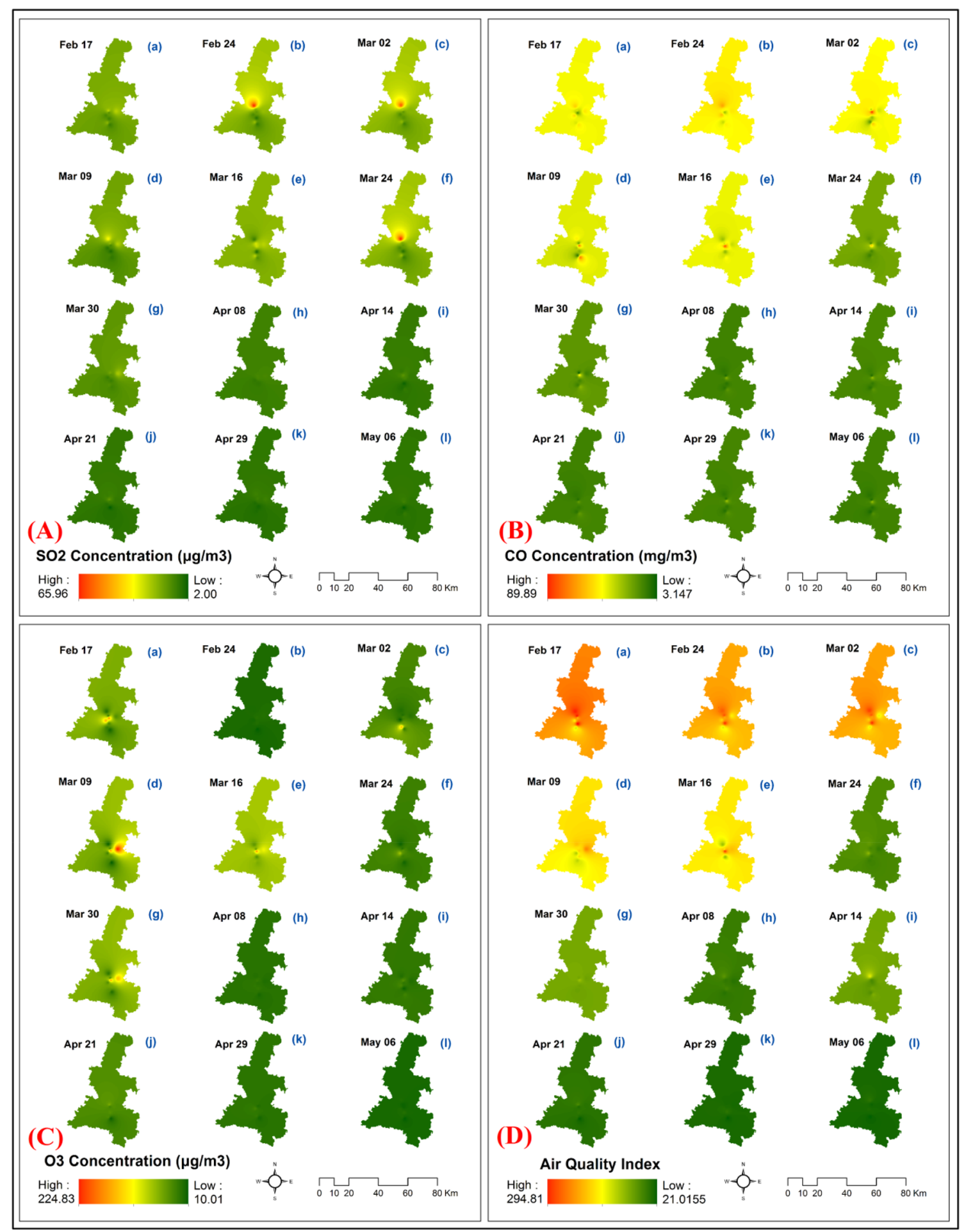

Fig. 3 Spatial status of $\mathbf{A ~} \mathrm{SO}_{2}, \mathbf{B ~ C O}, \mathbf{C ~ O}$, and $\mathbf{D} \mathrm{AQI}$ in pre-lockdown (a to e) and during lockdown period (f to $\mathbf{l}$ ) over Kolkata metropolitan area

- 45.17 and - 49.03 (Table 2). The upward and downward trend of concentration of $\mathrm{O}_{3}$ due to many causes such as, normally in India temperature and insolation starts rising from the end of the march and the highest temperature record in May, so the northward migration of the sun is the main natural phenomenon of increase of $\mathrm{O}_{3}$ (Gorai et al. 2017). As KMA is not an industrial area, therefore, human-made pollutants are produced by the transport of vehicles and domestic activities. Observation of this result indicates that the concentration of aerosols decreased 


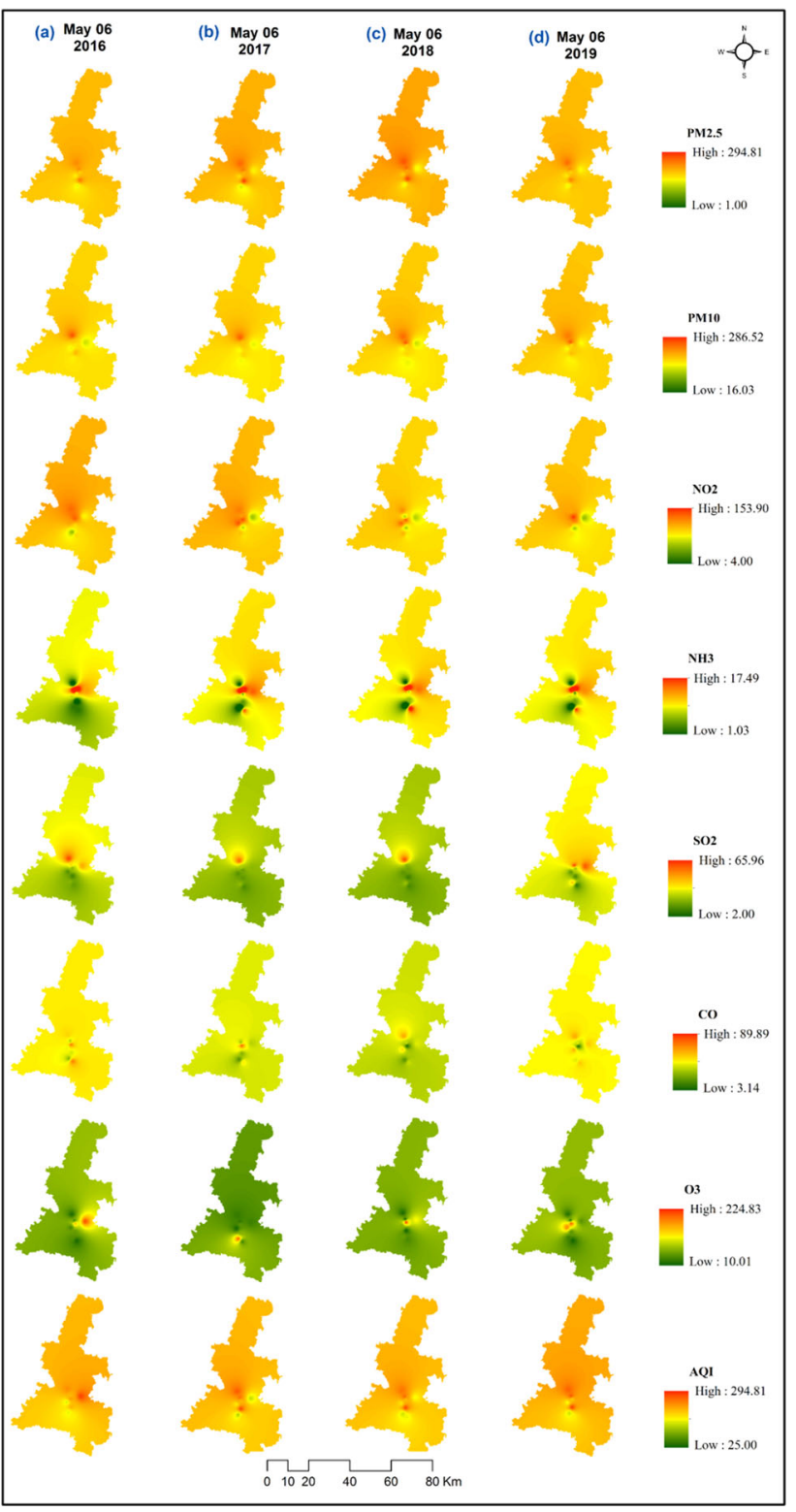

Fig. 4 Status of $\mathrm{PM}_{2.5}, \mathrm{PM}_{10}, \mathrm{NO}_{2}, \mathrm{NH}_{3}, \mathrm{SO}_{2}, \mathrm{CO}, \mathrm{O}_{3}$, and $\mathrm{AQI}$ in a 2016, b 2017, c 2018, and d 2019 over Kolkata metropolitan area

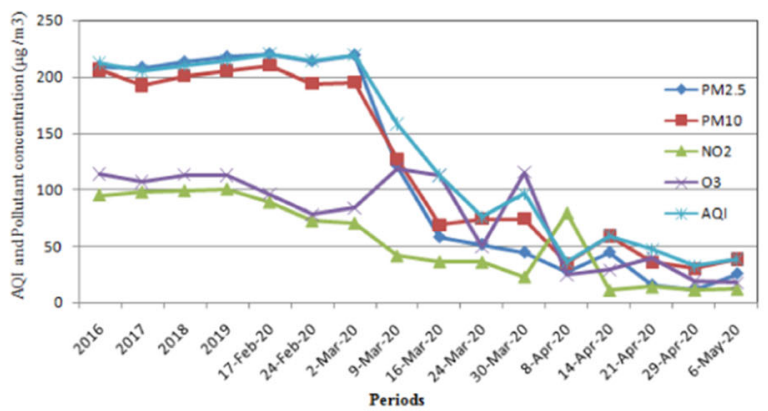

(a)

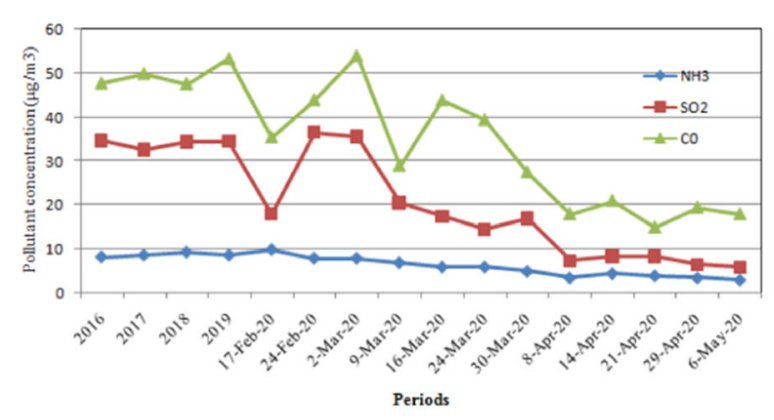

(b)

The AQI values of all stations have been calculated considering the Eq. 4 with the help of the air pollutant. During the lockdown time, the AQI have been improved into $63.12 \%$ from the average pre-lockdown AQI (Table 2). After the national wide lockdown the AQI improved in first week (30th March), Second week (8th April), third week (14th April), fourth week (21th April), fifth week (29th

Fig. 5 Trend of major pollutant in pre-lockdown and during lockdown period over Kolkata metropolitan area 
Table 2 Mean concentrations and variation of pollutants during 17th Feb to 16th Mar (Pre- lockdown) and 24th March to 6th May (During lockdown) in KMA

\begin{tabular}{lcrrr}
\hline Types of pollutants & Pre-lockdown & During lockdown & \multicolumn{2}{l}{ Overall variation } \\
\cline { 3 - 4 } & & & Net & $\%$ \\
\hline $\mathrm{PM}_{2.5}$ & 166.35 & 31.57 & -134.78 & -81.02 \\
$\mathrm{PM}_{10}$ & 158.84 & 49.36 & -109.49 & -68.93 \\
$\mathrm{NO}_{2}$ & 62.02 & 26.70 & -35.32 & -56.95 \\
$\mathrm{NH}_{3}$ & 7.79 & 4.21 & -3.58 & -45.96 \\
$\mathrm{SO}_{2}$ & 25.59 & 9.78 & -15.81 & -61.77 \\
$\mathrm{CO}$ & 41.31 & 22.65 & -18.66 & -45.17 \\
$\mathrm{O}_{3}$ & 85.71 & 43.69 & -42.02 & -49.03 \\
$\mathrm{AQI}$ & 185.66 & 68.47 & -117.19 & -63.12 \\
$\mathrm{AC}$ & 96.66 & 43.56 & -53.10 & -54.94 \\
\hline
\end{tabular}

Source National Air quality Index portal and Central Pollution Control Board, Govt. of India 2020

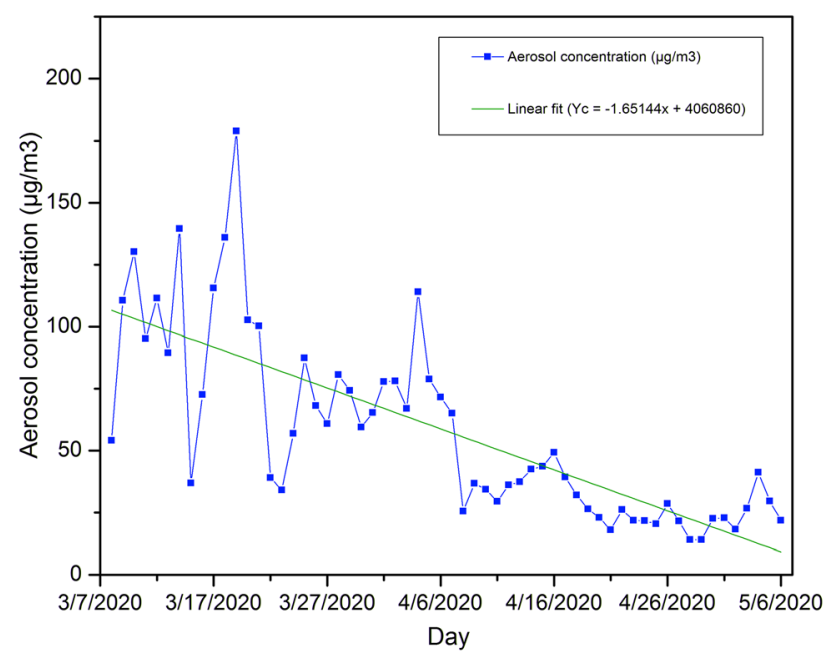

Fig. 6 Trend of aerosol concentration in pre-lockdown and during lockdown period over Kolkata metropolitan area

April) and six week (6th May) and the differences of AQI of these weeks are $38.09,80.61,68.22,74.70,82.50$ and 39.43 per cent respectively. The average differences of AQI from pre-lockdown to lockdown period are 171.16, which reveal a drastic change in the status of AQI in regard with the COVID-19 pandemic situation. After slide relaxation of lockdown (Except red zone), the AQI rate has increased minutely at the beginning of the third phase of the lockdown (After 3rd May) (Fig. 3.f). We have also seen the spatial distribution of AQI in different weeks of prelockdown periods. The poor AQI is shown in the middle part of KMA, which is very densely populated area, associated with more vehicles and existence of so many industries.

AQI depends mainly on the concentration of air pollutants in the atmosphere, such as $\mathrm{PM}_{2.5}, \mathrm{PM}_{10}, \mathrm{CO}, \mathrm{NO}_{2}$, $\mathrm{SO}_{2}, \mathrm{NH}_{3}$ and $\mathrm{O}_{3}$. So there are relation has been found among the AQI and these major air pollutants. The Spearman rank correlation coefficient is used to quantify
Table 3 Mann-Kendal and Sen's slope trends test estimation of major air pollutants

\begin{tabular}{|c|c|c|c|}
\hline \multicolumn{2}{|c|}{ Air pollutants } & \multicolumn{2}{|l|}{ KMA } \\
\hline & & Mann- Kendal Z & Sen's slope \\
\hline \multirow[t]{3}{*}{$\mathrm{PM}_{2.5}$} & Average & $-2.95 * * *$ & $-1.586^{* * *}$ \\
\hline & Minimum & $-2.01 * * *$ & $-1.214 * * *$ \\
\hline & Maximum & $-2.01 * *$ & $-1.463^{* *}$ \\
\hline \multirow[t]{3}{*}{$\mathrm{PM}_{10}$} & Average & $-2.82 * *$ & $-1.000^{* *}$ \\
\hline & Minimum & $-2.86^{* *}$ & $-1.414 * *$ \\
\hline & Maximum & $-2.56^{* *}$ & $-1.370^{* *}$ \\
\hline \multirow[t]{3}{*}{$\mathrm{NO}_{2}$} & Average & $-2.64 * * *$ & $-0.500^{* *}$ \\
\hline & Minimum & $-2.51 * *$ & $-0.167 * * *$ \\
\hline & Maximum & $-0.04 * * *$ & $-0.973 * * *$ \\
\hline \multirow[t]{3}{*}{$\mathrm{NH}_{3}$} & Average & $-0.52 * * *$ & $-0.051 * * *$ \\
\hline & Minimum & $-0.81 * *$ & $-0.040 * *$ \\
\hline & Maximum & $-0.74 * * *$ & $-0.512 * *$ \\
\hline \multirow[t]{3}{*}{$\mathrm{SO}_{2}$} & Average & $-0.91 * * *$ & $-0.183 * *$ \\
\hline & Minimum & $-0.64 * *$ & $-0.303 * *$ \\
\hline & Maximum & $-0.52 * * *$ & $-0.023 * *$ \\
\hline \multirow[t]{3}{*}{$\mathrm{CO}$} & Average & $-0.61 * * *$ & $-0.140 * * *$ \\
\hline & Minimum & $-0.61 * *$ & $-0.301 * *$ \\
\hline & Maximum & $-5.51 * *$ & $-0.249 * * *$ \\
\hline \multirow[t]{3}{*}{$\mathrm{O}_{3}$} & Average & $-0.34 * *$ & $-0.514 * * *$ \\
\hline & Minimum & $-0.02 * * *$ & $-0.472 * *$ \\
\hline & Maximum & $-0.01 * *$ & $-0.359 * * *$ \\
\hline
\end{tabular}

***,**, and $*$ are the significant at the $1 \%, 5 \%$, and $10 \%$ level of significance respectively

Source National Air quality Index portal and Central Pollution Control Board, Govt. of India 2020

the relationship between AQI and all major air pollutants. The result showed that all pollutants had a positive relationship, but that $\mathrm{PM}_{2.5}$ and $\mathrm{PM}_{10}$ had a high correlation with AQI and the value of correlation (r) was 0.91 and 0.86 
respectively. The concentration of $\mathrm{NO}_{2}, \mathrm{CO}$ and $\mathrm{SO}_{2}$ has a moderate positive relationship $(0.76,0.72$ and 0.68$)$, while $\mathrm{NH}_{3}$ and $\mathrm{O}_{3}$ have a low positive relationship, i.e. 0.58 and 0.51 .

\subsection{Changes of temperature during pre- lockdown and lockdown period}

This study included a trend analysis of the maximum, minimum and average temperature of the metropolitan Kolkata during the lockdown period (24th March to 6th May) in 2020 and at the same time for the previous four years, from 2016 to 2019. The most efficient Mann Kendall test with a 95\% significance level was used for this trend analysis. The result of the trend test was shown in Fig. 7 and Table 4. The initial time of the lockdown was spring time, and this time the Kolkata and as well as India moved towards the summer, so the maximum, minimum and average temperatures have been increasing over the years (Table 4). The trend of temperature during the COVID-19 pandemic lockdown period for maximum, minimum and average temperature are $0.091{ }^{\circ} \mathrm{C}, 0.118{ }^{\circ} \mathrm{C}$ and $0.106{ }^{\circ} \mathrm{C}$ per day. However, the trend of the previous year at the same time as the slight differs from the current year. Previous years have also seen an increase in the temperature trend, but the daily rising trend is more than in comparison to 2020s. In the year of 2016 the maximum, minimum and average trend were $0.103{ }^{\circ} \mathrm{C}, 0.128{ }^{\circ} \mathrm{C}$ and $0.119^{\circ} \mathrm{C}$ per day respectively. The trends for maximum, minimum and average $\left(0.100{ }^{\circ} \mathrm{C}, 0.118{ }^{\circ} \mathrm{C}\right.$ and $\left.0.111{ }^{\circ} \mathrm{C}\right)$ increased in 2017 also. The same increasing temperatures trend was observed in 2018s and 2019s. As a result of the trend analysis, it is clear that the increasing tendency of temperature in the lockdown period for 2020s is relatively slow in comparison to the previous years. The maximum, minimum and average temperature for April 2020s (Lockdown period) of KMA decreased by $2{ }^{\circ} \mathrm{C}, 1{ }^{\circ} \mathrm{C}$ and $1.5^{\circ} \mathrm{C}$ respectively in comparison with the previous year's average i.e. 1980 to 2019 (Normal year).

\subsection{Influence of air pollutants on temperature during pre lockdown and lockdown period}

From the above result, it has been shown that temperatures have decreased compared to the previous year. Due to the national wide large-scale forced lockdown, the level of pollutants in the air also decreased drastically. So we have established relationships between different air pollutants and temperatures because previous studies have shown that the temperature, relative humidity and wind direction in urban areas have an effect on air pollutants (Tayanç et al. 1997; Kinney 2008). The Spearman rank correlation result shows that all pollutants have a positive relationship with temperature. The correlation of the coefficients of $\mathrm{PM}_{2.5}$, $\mathrm{PM}_{10}$ and $\mathrm{O}_{3}$ has a high correlation value $(\mathrm{r}=0.84,0.76$, and 0.73), which means that the temperature has been strongly affected. On the other hand, $\mathrm{NO}_{2}, \mathrm{NH}_{3}, \mathrm{CO}, \mathrm{SO}_{2}$ $(\mathrm{r}=0.56,0.62,0.68$, and 0.57$)$ have comparatively low effect on lowering the temperature.

A Spearman rank correlation has also been established between the air quality index and the temperature. The relationship between the AQI and the temperature calculated in the pre-lockdown and lockdown phase. Both are positive, but the correlation ( $r$ ) value of the pre-lockdown period $(\mathrm{r}=0.52)$ is lower than the lockdown time $(\mathrm{r}=0.67)$.

\section{Discussion}

As the 3rd most populous metropolitan area in India (After Delhi and Mumbai), Kolkata also had a significant impact on climatic variability during the COVID-19 lockdown period. In this context, the impact on regional weather conditions focuses mainly on a gradual decrease in air
Fig. 7 Trend of maximum, minimum and average temperature from 1980 to 2020 of April month

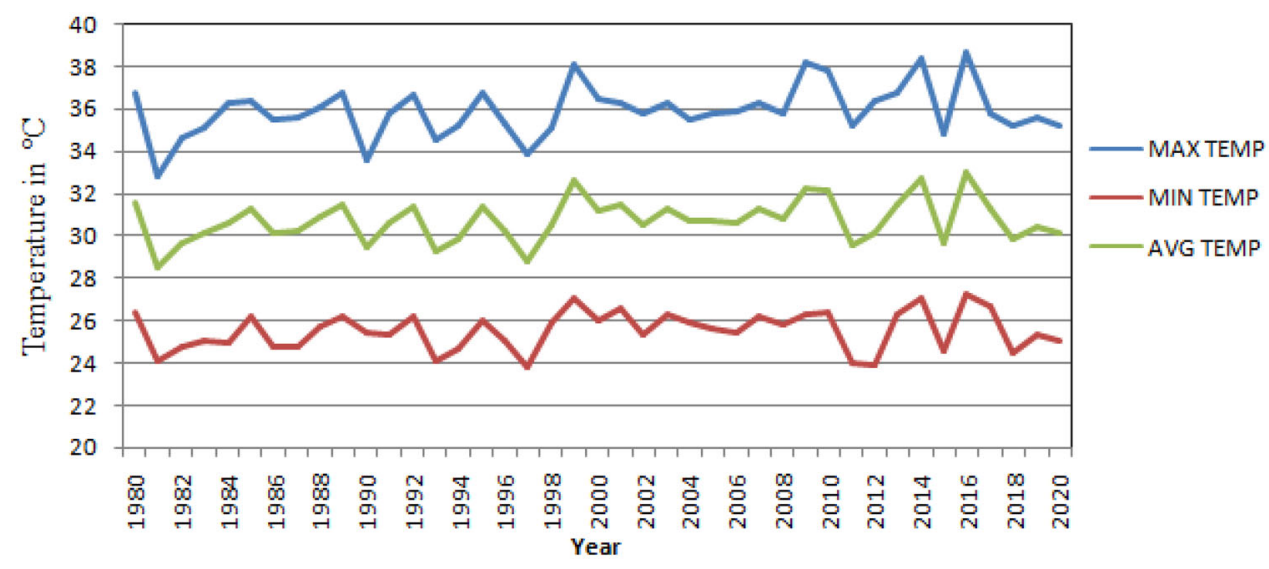


Table 4 Trend of temperature $\left({ }^{\circ} \mathrm{C}\right)$ during March to May in the year of 2016, 2017, 2018, 2019 and 2020

\begin{tabular}{|c|c|c|c|c|c|c|}
\hline \multirow[t]{2}{*}{ Period } & \multicolumn{3}{|c|}{ Mann- Kendal Z } & \multicolumn{3}{|l|}{ Sen's slope } \\
\hline & Maximum & Minimum & Average & Maximum & Minimum & Average \\
\hline March to May daily temperature (2020) & $8.08 * * *$ & $8.28 * * *$ & $8.44 * * *$ & 0.091 & 0.118 & 0.106 \\
\hline March to May daily temperature (2019) & $8.82 * * *$ & $9.25 * * *$ & $9.46^{* * *}$ & 0.104 & 0.130 & 0.119 \\
\hline March to May daily temperature (2018) & $9.41 * * *$ & $9.95 * * *$ & $10.01 * * *$ & 0.120 & 0.125 & 0.125 \\
\hline March to May daily temperature (2017) & $9.36 * * *$ & $10.07 * * *$ & $10.02 * * *$ & 0.100 & 0.118 & 0.111 \\
\hline March to May daily temperature (2016) & $9.40 * * *$ & $10.45 * * *$ & $10.25 * * *$ & 0.103 & 0.128 & 0.119 \\
\hline
\end{tabular}

$* * *, * *$, and $*$ are the significant at the $1 \%, 5 \%$, and $10 \%$ level of significance respectively

Source India Meteorological Department

temperature and an improvement in air quality during the lockdown period compared to the pre-lockdown period. The impact of air pollutants on the level of urban pollution is not a new phenomenon. Mayer et al. (2000) initially assessed the impact of different urban air pollutants on regional pollution levels. As a result, very few researchers have studied the impact of temperature variation on air pollutants in different megacities of India (Gurjar et al. 2004, 2016). Chowdhuri et al. (2020) have shown that there has been a substantial decrease in pre-monsoon lightning activity over the Kolkata megacity during the COVID-19 lockdown period. Reduction of $\mathrm{PM}_{10}, \mathrm{NO}_{2}, \mathrm{SO}_{2}, \mathrm{O}_{3}$ and aerosol concentrations in lower atmosphere due to COVID19 pandemic was the key cause of decline the pre-monsoon lightning rates over KMA.

The current study area of the metropolitan Kolkata is well recognised for its high level of pollution. As a result, the key pollution factors in Kolkata are uncontrolled vehicles, unplanned urbanization throughout the city, existence of sub-urban areas, and poorly maintained roads (Gurjar et al. 2016). The spread of the COVID-19 pandemic, the Government of India initiated a lockdown period (started on 24th March 2020) and as a result the concentration of different pollutants decreased significantly during this period. Due to the presence of low air pollutants in the atmosphere during the lockdown period the quality of the air not only improved but also the urban temperature gradually decreased. The result of our present objective shows that the concentration levels of $\mathrm{PM}_{2.5}$ and $\mathrm{PM}_{10}$ decreased by approximately -81.02 and -68.92 per cent during the lockdown period, which is a significant change in the atmospheric composition. The percentage of $\mathrm{NO}_{2}, \mathrm{SO}_{2}, \mathrm{NH}_{3}, \mathrm{CO}$ and $\mathrm{O}_{3}$ varies considerably and decreased by approximately $-56.95,-61.77$, $-45.95,-45.16$ and -49.027 per cent respectively. Depending on the air pollutants, there has also been a drastic change in the AQI rate in the COVID-19 pandemic, the AQI varying from pre-lockdown to lockdown period is
-63.12 per cent. On the effect of air pollutants and air quality, the average temperature of KMA also decreased significantly about $1.5^{\circ} \mathrm{C}$ and the maximum temperature also decreased about $2{ }^{\circ} \mathrm{C}$ during the month of April. Finally, it is considered that, among other cities in India, Kolkata also had some effect on the weather conditions during the lockdown period of the COVID-19 pandemic from March to May.

\section{Conclusion}

The present research shows that ambient air pollutants are closely connected to climatic variability in the KMA. Not only climatic factors, but also $\mathrm{PM}_{2.5}, \mathrm{PM}_{10}, \mathrm{NO}_{2}, \mathrm{NH}_{3}$, $\mathrm{SO}_{2}, \mathrm{CO}, \mathrm{O}_{3}$, and aerosols levels plays a major role in the modification of short term weather, such as temperature. The COVID-19 pandemic lockdown has given us the opportunity for doing this type of experiment. Previous many studies showed that the ambient air quality was improved during the strict lockdown. But Impact of COVID-19 lockdown, especially on climatic variability (temperature) has been studied as an experiment in metropolitan city of Kolkata, India. During this lockdown, the level of air pollution in this megacity has dropped to an unimaginable limit. Aerosol, $\mathrm{PM}_{2.5}, \mathrm{PM}_{10}, \mathrm{NO}_{2}, \mathrm{NH}_{3}, \mathrm{SO}_{2}$, $\mathrm{CO}$ and $\mathrm{O}_{3}$ decreased by $-54.94 \%,-81.02 \%$, $-68.92 \%,-56.95 \%, \quad-45.95 \%,-61.77 \%$, $-57.57 \%$ and -40.67 respectively from the pre-lockdown average. Due to the low level of air pollution, the temperature of KMA has decreased in this time. The trend of temperature (March to April) during the COVID-19 pandemic lockdown for maximum, minimum and average temperature are $0.091{ }^{\circ} \mathrm{C}, 0.118{ }^{\circ} \mathrm{C}$ and $0.106{ }^{\circ} \mathrm{C}$ per day which lower than normal year (2016 to 2019). The maximum, minimum and average temperature for April 2020 (Lockdown period) of KMA decreased by $2{ }^{\circ} \mathrm{C}, 1{ }^{\circ} \mathrm{C}$ and 
$1.5{ }^{\circ} \mathrm{C}$ respectively in comparison to the previous year's average i.e. 1980 to 2019.

This is clear from the results that the lockdown has contribute to a major improvement in air quality, and might function as an important way of reducing emissions and eventually it will have an influence on the urban sustainability. So, in the coming years, such a short time lockdown may be implemented to control unhealthful air pollution in the target urban area. However, this research outcome will also provide information to the decision makers and other management authorities adopting the appropriate strategies in regard with the air pollutants and global warming problems. The research is of immense significance able to estimate the relationship between air pollutants and associated atmospheric conditions, such as lower atmospheric temperature and greenhouse gases. This research finding can be used to assist the future study of urban heat island and the associated overall environmental sustainability. Air pollutants are the major determinants of urban heat, so impact of air pollutants can be considered as significant factors in further studies related to urban heat islands. Urban planners of KMA should take appropriate action, such as reducing traffic congestion, the odd-even vehicle rule, the pledge to drive one day less a week, and a strict rule for the toxic industry to reduce emissions of major air pollutants.

Author contributions I C: Formal analysis, Collected the Data, Writing and Editing, Prepared diagrams and Maps. S C P: Conceptualization, Methodology, Investigation, Formal analysis, Visualization, Writing-Original Draft, Writing and Editing. A A: Formal analysis, Writing-Original Draft, Writing and Editing. $\mathrm{P} T \mathrm{~T} \mathrm{~N}$ : Writing-Original Draft, Writing and Editing. P R: Writing-Original Draft, Writing and Editing. A S: Collected the Data, Prepared diagrams and Framework of the Study. M G: Formal analysis, Writing-Original Draft, Writing and Editing. R C: Writing-Original Draft, Writing and Editing.

Funding The work carried out without any financial assistance from any funding organization.

\section{Declarations}

Conflict of interest There is no conflict of interest among the authors.

\section{References}

Alam K, Qureshi S, Blaschke T (2011) Monitoring spatio-temporal aerosol patterns over Pakistan based on MODIS, TOMS and MISR satellite data and a HYSPLIT model. Atmos Environ 45:4641-4651

Bashir M, Shahzad A, Komal B, Tan D (2021) Nexus between temperature and COVID-19 pandemic: a meta-analysis
Bashir MF, Benjiang MA, Shahzad L (2020) A brief review of socioeconomic and environmental impact of Covid-19. Air Qual Atmos Health 13:1403-1409

Bilal MFB, Komal B, Benghoul M et al (2021) Nexus between the COVID-19 dynamics and environmental pollution indicators in South America. Risk Manag Healthc Policy 14:67

CPCB|Central Pollution Control Board (2020) https://cpcb.nic.in/. Accessed 21 May 2020

Chang HH, Hu X, Liu Y (2014) Calibrating MODIS aerosol optical depth for predicting daily PM 2.5 concentrations via statistical downscaling. J Eposure Sci Environ Epidemiol 24:398-404

Chelani AB, Rao CC, Phadke KM, Hasan MZ (2002) Formation of an air quality index in India. Int J Environ Stud 59:331-342

Chowdhuri I, Pal SC, Saha A et al (2020) Significant decrease of lightning activities during COVID-19 lockdown period over Kolkata megacity in India. Sci Total Environ 747:141321

Da Silva RM, Santos CA, Moreira M et al (2015) Rainfall and river flow trends using Mann-Kendall and Sen's slope estimator statistical tests in the Cobres River basin. Nat Hazards 77:1205-1221

Eydoux C, Fattorini V, Shannon A et al (2021) A Fluorescence-based high throughput-screening assay for the SARS-CoV RNA synthesis complex. J Virol Methods 288:114013

Gilbert RO (1987) Statistical methods for environmental pollution monitoring. John Wiley \& Sons

Gocic M, Trajkovic S (2013) Analysis of changes in meteorological variables using Mann-Kendall and Sen's slope estimator statistical tests in Serbia. Glob Planet Change 100:172-182

Gorai AK, Tchounwou PB, Mitra G (2017) Spatial variation of ground level ozone concentrations and its health impacts in an urban area in India. Aerosol Air Qual Res 17:951

Gupta A, Dhir A (2019) Air quality assessment of Mandi Gobindgarh city of Punjab, India. Environ Dev Sustain 21:879-893

Gupta AK, Karar K, Ayoob S, John K (2008) Spatio-temporal characteristics of gaseous and particulate pollutants in an urban region of Kolkata, India. Atmos Res 87:103-115. https://doi.org/ 10.1016/j.atmosres.2007.07.008

Gurjar BR, Jain A, Sharma A et al (2010) Human health risks in megacities due to air pollution. Atmos Environ 44:4606-4613

Gurjar BR, Ravindra K, Nagpure AS (2016) Air pollution trends over Indian megacities and their local-to-global implications. Atmos Environ 142:475-495

Gurjar BR, Van Aardenne JA, Lelieveld J, Mohan M (2004) Emission estimates and trends (1990-2000) for megacity Delhi and implications. Atmos Environ 38:5663-5681

Hamed KH, Rao AR (1998) A modified Mann-Kendall trend test for autocorrelated data. J Hydrol 204:182-196

Haque MS, Singh RB (2017) Air pollution and human health in Kolkata, India: a case study. Climate 5:77. https://doi.org/10. 3390/cli5040077

Kaufman YJ, Fraser RS (1983) Light extinction by aerosols during summer air pollution. J Clim Appl Meteorol 22:1694-1706

Kendall M (1975) Rank correlation methods (4th edn) charles griffin. San Francisco, CA 8

Kinney PL (2008) Climate change, air quality, and human health. Am J Prev Med 35:459-467. https://doi.org/10.1016/j.amepre.2008. 08.025

Kumar A, Goyal P (2011) Forecasting of daily air quality index in Delhi. Sci Total Environ 409:5517-5523

Li H, Wang J, Li R, Lu H (2019) Novel analysis-forecast system based on multi-objective optimization for air quality index. J Clean Prod 208:1365-1383

Mahato S, Pal S, Ghosh KG (2020) Effect of lockdown amid COVID19 pandemic on air quality of the megacity Delhi, India. Sci Total Environ 730:139086 
Mandal I, Pal S (2020) COVID-19 pandemic persuaded lockdown effects on environment over stone quarrying and crushing areas. Sci Total Environ 732:139281

Mann HB (1945) Nonparametric tests against trend. Econ J Econ Soc 13:245-259

Mayer M, Wang C, Webster M, Prinn RG (2000) Linking local air pollution to global chemistry and climate. J Geophys Res Atmos 105:22869-22896

Mhawish A, Kumar M, Mishra AK et al (2018) Remote sensing of aerosols from space: retrieval of properties and applications. In: Wang J, Hu Y, Kokhanovsky AA, Islam T (eds) Remote sensing of aerosols, clouds, and precipitation. Elsevier, Amsterdam, pp 45-83

Mondal P, Reichelt-Brushett AJ, Jonathan MP et al (2018) Pollution evaluation of total and acid-leachable trace elements in surface sediments of Hooghly River Estuary and Sundarban Mangrove Wetland (India). Environ Sci Pollut Res 25:5681-5699

Muhammad S, Long X, Salman M (2020) COVID-19 pandemic and environmental pollution: a blessing in disguise? Sci Total Environ 728:138820

National Air Quality Index (2020). https://app.cpcbccr.com/AQI_ India/. Accessed 21 May 2020

Pal SC, Chowdhuri I, Saha A et al (2020) Improvement in ambientair-quality reduced temperature during the COVID-19 lockdown period in India. Environ Dev Sustain. https://doi.org/10.1007/ s10668-020-01034-z

Pal SC, Saha A, Chowdhuri I et al (2021) Threats of unplanned movement of migrant workers for sudden spurt of COVID-19 pandemic in India. Cities 109:103035. https://doi.org/10.1016/j. cities.2020.103035
Sen PK (1968) Estimates of the regression coefficient based on Kendall's tau. J Am Stat Assoc 63:1379-1389

Sharma M, Maheshwari M, Sengupta B, Shukla BP (2003) Design of a website for dissemination of air quality index in India. Environ Model Softw 18:405-411

Sharma S, Zhang M et al (2020) Effect of restricted emissions during COVID-19 on air quality in India. Sci Total Environ 728:138878. https://doi.org/10.1016/j.scitotenv.2020.138878

Shaw N, Gorai AK (2018) Study of aerosol optical depth using satellite data (MODIS Aqua) over Indian Territory and its relation to particulate matter concentration. Environment, Development and Sustainability 1-15

Smith WH (1970) (1974) Air pollution-effects on the structure and function of the temperate forest ecosystem. Environ Pollut 6:111-129

Spiroska J, Rahman MA, Pal S (2011) Air pollution in Kolkata: an analysis of current status and interrelation between different factors. SEEU REV 8:187

Tayanç M, Karaca M, Yenigün O (1997) Annual and seasonal air temperature trend patterns of climate change and urbanization effects in relation to air pollutants in Turkey. J Geophys Res Atmos 102:1909-1919. https://doi.org/10.1029/96JD02108

Yunus AP, Masago Y, Hijioka Y (2020) COVID-19 and surface water quality: improved lake water quality during the lockdown. Sci Total Environ 731:139012

Publisher's Note Springer Nature remains neutral with regard to jurisdictional claims in published maps and institutional affiliations.

\section{Authors and Affiliations}

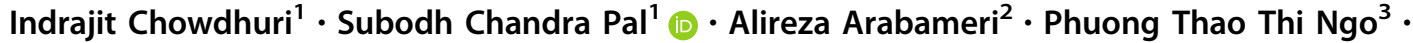 Paramita Roy ${ }^{1} \cdot$ Asish Saha $^{1} \cdot$ Manoranjan Ghosh ${ }^{4} \cdot$ Rabin Chakrabortty $^{1}$}

Subodh Chandra Pal

geo.subodh@gmail.com

Indrajit Chowdhuri

indrajitchowdhuri@gmail.com

Alireza Arabameri

alireza.ameri91@yahoo.com

Phuong Thao Thi Ngo

Ngotphuongthao5@duytan.edu.vn

Paramita Roy

paramitaroy95@gmail.com

Asish Saha

asishsaha01@gmail.com
Manoranjan Ghosh

ghoshmanoranjan.99@gmail.com

Rabin Chakrabortty

rabingeo8@gmail.com

1 Department of Geography, The University of Burdwan, Bardhaman, West Bengal 713104, India

2 Department of Geomorphology, Tarbiat Modares University, 14117-13116 Tehran, Iran

3 Institute of Research and Development, Duy Tan University, Da Nang 550000, Vietnam

4 Rural Development Centre, Indian Institute of Technology, Kharagpur, West Bengal 721302, India 